УДК 331. 1

\title{
ОСОБЕННОСТИ СОДЕРЖАНИЯ И ТИПЫ КАДРОВОЙ ПОЛИТИКИ НА ОТЕЧЕСТВЕННЫХ ПРЕДПРИЯТИЯХ ТРАНСПОРТА
}

\author{
Данилина Елена Ивановна \\ Доктор экономических наук, профессор \\ МИРЭА - Российский технологический университет
}

\begin{abstract}
Аннотация: В статье показана эволюция взглядов на управление человеческими ресурсами, указаны особенности кадровой политики, в том числе в транспортном комплексе. Представлены результаты анализа проводимой кадровой политики в ОАО «Российские железные дороги». По результатам исследования выявлена особая роль и значение кадровой политики для предприятий транспорта.

Ключевые слова: человеческие ресурсы, кадровая политика, управление персоналом, транспортный комплекс.

\section{FEATURES OF THE CONTENT AND TYPES OF PERSONNEL POLICY AT DOMESTIC TRANSPORT ENTERPRISES}

\section{Danilina Elena Ivanovna}

\begin{abstract}
The article shows the evolution of views on human resource management, the features of personnel policy, including in the transport complex, are indicated. The results of the analysis of the personnel policy carried out in JSC "Russian Railways"are presented. According to the results of the study, the special role and importance of personnel policy for transport enterprises is revealed.
\end{abstract}

Key words: human resources, personnel policy, personnel management, transport complex.

Важнейшей характеристикой современного общества являются существенные изменения в мышлении рабочей силы и поведении рынка труда. Движимый ускорением связности и когнитивных технологий, меняется характер рабочих мест.

Происходящие изменения обуславливают необходимость разработки новых правил для персонала, внедрения новых подходов к организации, мотивации, управления и привлечения рабочей силы 21 века. Для того, чтобы 
быстро реагировать на возрастающие требования к профессиональным навыкам сотрудников, предприятиям необходима гибкая кадровая политика, которая способна обеспечить вклад инвестиций в развитие человеческих ресурсов.

Результаты деятельности отдельных организаций и экономики в целом во многом зависит от качества человеческих ресурсов. Сильное управление человеческими ресурсами позволяет организации повысить производительность, укрепить репутацию, обеспечить финансовый и интеллектуальный рост компании.

Хронологию эволюции управления человеческими ресурсами в том виде, в каком она существует сегодня можно разбить на несколько периодов:

- 19 век - «управление персоналом». Рост промышленного производства привел к дефициту рабочей силы. В поисках решения проблемы стали применяться научные идеи, направленные на увеличение производительности труда, в частности научная теория менеджмента $Ф$. Тейлора, связанная с управлением персоналом.

- 20 век - «управление человеческими ресурсами». Исследования Э. Хоторна опровергли научный подход Тейлора к управлению повышением производительности и показали, что основными факторами мотивации и производительности являются не денежные факторы. На основе этой поведенческой перспективы появилось множество новых теорий, и в обиход вошел термин «управление человеческими ресурсами».

21 век - «Стратегическое управление человеческими ресурсами» и «управление человеческим капиталом». Рост технологических и наукоемких отраслей усиливает глобальную конкуренцию. Как следствие, многие компании взяли на вооружение стратегическую практику управления человеческими ресурсами, чтобы оказать долгосрочное влияние на корпоративный успех, и называют свою деятельность управлением человеческим капиталом.

Транспортная отрасль имеет ключевое значение для эффективной работы экономики и способствует решению целого ряда общенациональных задач, связанных с улучшением качества жизни населения. Надежным залогом успешного решения всего комплекса задач, стоящих перед транспортной отраслью выступает качество персонала.

Повышение качественного состава сотрудников за счет привлечения квалифицированных, талантливых и мотивированных сотрудников является важной частью управления персоналом. Управление персоналом является 
кадровой функцией управления, и часто используется как синоним понятия «управление человеческими ресурсами».

В современной научной литературе не существует стандартного определения термина «управление персоналом»: одни авторы определяют его с точки зрения выполняемых функций,[2, с. 114], [5, с. 114], [7, с. 114] другие - с точки зрения системного подхода к управлению персоналом, [7, с. 114], [1, с. $114]$, [6, с. 114], [9, с. 114], а третьи - с точки зрения человеческих отношений $[3$, c. 114$],[4$, c. 114$],[11$, c. 114$]$.

В данном исследовании, отраженном в статье, под управлением персоналом понимается комплекс мер, которые позволят сотрудникам максимально реализовать свои внутренние способности и обеспечить предприятию, частью которого они являются определяющее конкурентное преимущество и оптимальные результаты.

Последовательный подход к управлению персоналом реализуется посредством эффективной кадровой политики. Поскольку не существует единого алгоритма взаимодействия работодателя с сотрудниками и каждое предприятие разрабатывает собственный вариант, четко установленной типологии кадровой политики отсутствует.

Характерные особенности кадровой политики в транспортном комплексе определяются отраслевой спецификой:

- Высокая социальная значимость отрасли;

- Более половины работников заняты на предприятиях государственных и муниципальных форм собственности;

- Наличие стабильного спроса на квалифицированные кадры;

- Инновационное развитие и цифровая трансформация транспортного комплекса;

Изучение научной литературы по управлению человеческими ресурсами позволила выстроить классификацию типов кадровой политики в транспортной отрасли.

По классификационному признаку по уровню управления выделяют типы кадровой политики: государственная кадровая политика, кадровая политика организаций; по методам реализации отмечают активную, пассивную, реактивную и превентивную. По степени открытости - открытую и закрытую

В зависимости от уровня управления кадровая политика разделяется на государственную и кадровую политику транспортных предприятий. 
Государственная кадровая политика является одним из важнейших направлений деятельности органов федеральных и региональных органов власти по регулированию рынка труда и обеспечению потребностей транспортной отрасли в высококвалифицированных, компетентных и конкурентоспособных кадрах.

Государственная кадровая политика является одним из важнейших направлений деятельности органов федеральных и муниципальных органов власти по регулированию рынка труда и повышению качества человеческого капитала страны и сосредоточена на таких аспектах, как квалификация рабочей силы, уровень образования, здоровье и социальная поддержка населения.

В настоящее время в Российской Федерации реализуются стратегические государственные программы, основными целями которой является повышение качества транспортной инфраструктуры и транспортных услуг, усиление конкурентоспособности транспортного комплекса, а также повышение безопасности и устойчивости транспортной системы. Достижение поставленных задач возможно только при условии обеспечения отрасли достаточным количеством компетентных, профессиональных специалистов.

Основными задачами кадровой политики в сфере транспорта являются:

- Гарантированное обеспечение потребностей отрасли в компетентных специалистах, воспроизводство кадрового потенциала, повышение качества подготовки и профессионализма работников;

- Наделение работников новыми компетенциями в соответствии с потребностями отрасли;

- Формирование научно-исследовательского и научнотехнологического потенциала развития транспортной отрасли за счет подготовки научных кадров;

- Создание условий для развития и оптимизации системы профессионального транспортного образования.

Кадровая политика предприятий представляет собой инструмент принятия кадровых решений и содержит формальные правила и принципы, на основе которых руководство намеревается управлять человеческими ресурсами и что ожидается от сотрудников на рабочем месте. Кадровая политика отражает, как сотрудники ценятся или не ценятся как ресурс, а также выражает управленческую позицию в отношении принятия решений по кадровым вопросам и роли, которые будет играть каждый участник трудовых отношений. 
В отсутствии четкой, понятной как для руководства, так и для персонала, политики, существует риск принятия ошибочных, необдуманных решений, которые могут демотивировать сотрудников и снизить эффективность работы все организации.

В зависимости от методов реализации различают активную, пассивную, реактивную и превентивную кадровую политику. Укажем преимущества и недостатки данных видов кадровых политик

Активная кадровая политика к преимуществам относится наличие средств и возможностей для прогнозирования и управления кадровой ситуацией, а недостатком является то, что требует значительных инвестиций в развитие персонала, а также длительных исследований и комплексного подхода. Пассивная кадровая политика имеет преимущества в том, что не требует дополнительных затрат на развитие персонала, а недостаток отсутствие обоснованной программы кадровой работы. Реактивная кадровая политика имеет преимущество, что осуществляет текущий контроль за кадровой ситуацией, а недостаток - функции анализа и прогнозирования в ней не осуществляются. Все решения принимаются лишь по факту возникновения ситуаций, требующих реагирования. Превентивная кадровая политика среди преимуществ выделяет то, что предусмотрено осуществление прогнозирования кадровой ситуации и при правильной реализации позволит обеспечить высокий уровень стабильности компании. $\mathrm{K}$ недостаткам относится отсутствие инструментов управления и воздействия на текущую кадровую ситуацию. Данный тип кадровой политики малоприменим в транспортной отрасли, где точные и достоверные прогнозы делать трудно

Активная кадровая политика является наиболее продуктивной и отвечает современным принципам управления человеческими ресурсами. Данный тип кадровой политики предполагает наличие средне- и долгосрочное прогнозирования, средств непосредственного реагирования на определенную ситуацию. Кадровыми службами проводится аналитика внутренних и внешних факторов, влияющих на исполнение кадровых программ, проводится мониторинг системы управления человеческими ресурсами, формируются инструменты развития кадрового потенциала организации.

Примером активной кадровой политики является политика, проводимая ОАО «Российские железные дороги». В рамках принятой долгосрочной программы развития до 2025 года [19, с. 114] выделен отдельный пункт «Кадровая и социальная политика», согласно которому к 2025 году планируется сократить численность сотрудников на 4,2\%. Снижение 
численности планируется осуществлять с учетом естественного оттока персонала, перераспределения трудовых ресурсов внутри компании и переобучения новым профессиям. В то же время в соответствии с долгосрочной кадровой стратегией компании в связи с внедрением инновационных транспортных технологий и цифровизации транспорта планируется укрепить кадровый потенциал за счет сотрудников новых профессиональных квалификаций, профессий и должностей.

Пассивная кадровая политика - тип политики, противоположный активному виду. Взаимодействие руководства с сотрудниками, анализ кадровой ситуации и прогнозирование развития человеческих ресурсов носит ситуативный, несистемный характер. Несмотря на то, что в рамках пассивного подхода к кадровой политике не требуется дополнительных затрат на развитие персонала, эффективность такой политики слабо либо вообще не контролируется и не прогнозируется. Проведение пассивной кадровой политики характерно для небольших автотранспортных компаний, деятельность которых связана с оказанием разовых транспортных услуг.

Аналогично пассивному формату, при реактивном типе кадровой политики функции анализа и прогнозирования не осуществляются. У руководства компании, как правило, отсутствуют достаточные ресурсы для разработки полноценной стратегии. При этом руководством осознается необходимость управления персоналом, но оно «включается» лишь при наступлении какого-либо события.

Реактивная кадровая политика характерна, как правило, для небольших автотранспортных компаний, муниципальных унитарных трамвайнотроллейбусных предприятий и т.д.

Превентивная кадровая политика представляет собой тип руководства, в котором ключевая роль отводится прогнозированию, акцентируя внимание на укрепление кадрового потенциала в долгосрочном будущем.

В зависимости от степени открытия кадровую политику может быть открытой или закрытой.

Открытая кадровая политика характерна для компаний, которые открыты для взаимодействия с внешней средой. Набор сотрудников на любые вакансии осуществляется из открытых внешних источников. Характерными особенностями открытой кадровой политики является:

- Активная стратегия «охоты за головами» (хедхантинг);

- Совершенный механизм адаптации сотрудников; 
- Содействие и поощрение индивидуальности и самостоятельности работников;

- Вертикальная ротация затруднена, поскольку руководитель любого уровня в любой момент может быть привлечен со стороны;

- Эффективная мотивация профессионального развития из-за высокой конкуренции внутри трудового коллектива;

- Распространенным методом стимулирования является метод «кнута и пряника».

В качестве примера кадровой политики открытого типа можно отметить кадровые политики многих автотранспортных компаний, муниципальных предприятий общественного транспорта и т.д.

Закрытая кадровая политика акцентирует внимание на собственных кадрах. К характерным особенностям данного типа кадровой политики можно отнести:

- Из внешних источников новые сотрудники привлекаются только на низшие должности;

- Сотрудникам обеспечивается карьерный рост внутри компании;

- Процесс адаптации нацелен на вовлечение в корпоративную культуру;

- Равноценное применение как материальной, так и моральной мотивации;

- Слабая мотивация профессионального развития из-за недостаточного «притока кадров» из внешних источников.

Закрытая кадровая политика характерна для РЖД, авиакомпаний, предприятий внутреннего водного пассажирского транспорта и предприятий морского транспорта.

Существенное влияние на выбор кадровой политики оказывает сложившаяся ситуация на рынке труда. В условиях избыточного предложения целесообразным выбором является открытая кадровая политика. В случае дефицита талантливых кандидатов предпочтительна закрытая кадровая политика.

В зависимости от источника возникновения кадровая политика может быть:

- Базовой (исходной). Устанавливается высшим руководством намеренно, чтобы направлять исполнительное мышление на различных уровнях. 
- Апелляционной. Формируется в соответствии с определенными требованиями специфических ситуаций, которые не были предусмотрены в более ранней кадровой политике. Такие запросы обычно поступают от сотрудников, которые не справлялись с делами на основе рекомендаций, предлагаемых существующей кадровой политикой.

- Навязанной. Формируется под давлением внешних структур, таких как государственные органы власти, профессиональные ассоциации и союзы.

Имплицитная политика означает политику, которая исходит из поведения участников (например, дресс-код, мягкий тон во время разговора с клиентом и т.д.). Она возникает там, где существующие политики не применяются. Руководящие принципы могут быть предоставлены лицами, принимающими решения, бессознательно и стать подразумеваемой политикой.

В зависимости от описания уровней выделяют:

- Общую кадровую политику, которая отражает основную философию и приоритеты высшего руководства при разработке стратегии развития компании.

- Конкретную кадровую политику, которая охватывает решения, относящихся к основным управленческим функциям: планирование, найм, вознаграждение и мотивация, организация, развитие и т.д. В то же время такая политика должна соответствовать базовым рамкам, предлагаемым общей политикой.

В зависимости от размера организации, типа бизнеса и бизнес-модели кадровая политика компаний может или должна содержать множество элементов, включая следующие:

- Подбор персонала: процесс должен быть прозрачным и беспристрастным, чтобы привести к найму лучших специалистов, основанного на заслугах и соответствии целям, ценностям и философии данной компании.

- Соблюдение правовых норм: соблюдение закона является обязанностью каждого работодателя и работника.

- Оплата труда и льготы: общая сумма оплаты труда должна включать базовую заработную плату, стимулирующие выплаты, неденежную компенсацию и льготы.

- Политика времени: должны быть определены график работы, перерывы, праздники, больничные и личные отпуска.

- Оценка производительности: следует признавать преуспевающих сотрудников, а работники, испытывающие трудности, должны иметь шанс на 
успех, при этом неся ответственность за невысокую производительность. Двусторонний диалог может помочь определить, были ли предоставлены сотруднику ресурсы и инструменты, необходимые для достижения успеха, и устранить проблемы, связанные с конкретной производительностью или поведением. Оценки могут привести к повышению общей производительности, признанию пробелов в обучении или навыках, а также к возможному понижению в должности, переводу или увольнению. Оценки также полезны для новых сотрудников как инструмент для сообщения об ожидаемых результатах.

- Увольнение. Работодатели должны разработать стандартные процедуры, регулирующие добровольное и недобровольное увольнение. Принятие и строгое соблюдение установленных политик и процедур снижает риск судебных исков сотрудников и обеспечивает соблюдение компанией соответствующих государственных и федеральных законов.

Таким образом, кадровая политика в том или ином виде существует на любом предприятии, где имеются трудовые отношения между работником и работодателем. Рассмотренные выше типы кадровой политики транспортные компании на практике редко применяют полностью открытую или закрытую модель, а в той или иной мере сочетают их отдельные элементы.

\section{Список литературы}

[1] Базаров Т.Ю. Управление персоналом. М.: Академия, 2020. 320 с.

[2] Балашов А.П. Основы теории управления. М.: Вузовский учебник, $2015,280 \mathrm{c}$.

[3] Brech Edward Franz Leopold. Principle and Practice of Management. Longman, 1975, $1081 \mathrm{p}$.

[4] Веснин, В.Р. Управление человеческими ресурсами: теория и практика: учебник / В. Р. Веснин. - Москва: Проспект, 2017. 688 с.

[5] Edwin B. Flippo. Personnel Management. McGraw-Hill, 1984, 601 p.

[6] Егоршин А.П. Основы управления персоналом. М.: Инфра-М, 2015. $352 \mathrm{c}$.

[7] Дуракова И.Б. Управление персоналом. Учебник /И.Б. Дуракова, Л.П. Волкова, С.М. Талтынов и др.; ИНФРА -М; Москва 2016. 569с.

[8] Кибанов А.Я. Управление персоналом организации: учебник / под ред. А.Я. Кибанова.- 4-е изд., доп. и перераб. М.: ИНФРА-М, 2020. 695 с 
[9] Одегов, Ю.Г. Управление персоналом: учебник и практикум для академического бакалавриата / Ю. Г. Одегов, Г. Г. Руденко. М.: Юрайт, 2018. $466 \mathrm{c}$.

[10] Распоряжение Правительства РФ от 19.03.2019 № 466p. «Об утверждении долгосрочной программы развития ОАО "РЖД" до 2025 года. https://old-doc.rzd.ru/dbmm/download?vp=4\&load=y\&col_id=9111\&id=4962

[11] Чуланова О. Л. Компетентностный подход в управлении персоналом: учебник / О.Л. Чуланова. — М: ИНФРА-М, 2020. 368 с

(C) Данилина Е.И., 2021 